\title{
Los primeros folletos de ediciones "Acción Obrera”. Una experiencia editorial en los orígenes del trotskismo argentino (1938-1941)
}

\author{
The first pamphlets of "Acción Obrera" editions. \\ An editorial experience in the origins of Argentinian Trotskyism
}

Constanza Bosch Alessio

\begin{abstract}
Resumen
Liborio Justo entre 1938 y 1941, editó una serie de diez folletos bajo el sello de Ediciones “Acción Obrera”. El presente artículo analiza las primeras tres publicaciones, las cuales reconstruyen los inicios del trotskismo en Argentina y América Latina, plantean los vínculos entre las agrupaciones que adherían al "movimiento cuartainternacionalista”, reproducen los debates y parte de la correspondencia entre ellos, y los sitúa en el contexto mundial del derrumbe la Tercera Internacional, el ascenso del fascismo y las implicancias de la Segunda Guerra Mundial.
\end{abstract}

Palabras clave: Trotskismo argentino - Publicaciones trotskistas Grupo Obrero Revolucionario - Liborio Justo - Cuarta Internacional

\footnotetext{
${ }^{*}$ Argentina. Profesora en Historia por la Universidad Nacional de Córdoba. Becaria Doctoral del Consejo Nacional de Investigaciones Científicas y Técnicas de Argentina. Miembro del Programa de Historia Contemporánea del Centro de Investigaciones y Estudios sobre Cultura y Sociedad, cobosch@gmail.com
} 


\begin{abstract}
Liborio Justo published between 1938 and 1941 a series of ten pamphlets under the seal of "Acción Obrera" publishers. This article analyzes the first three publications, which reconstruct the beginnings of Trotskyism in Argentina and Latin America. The pamphlets describe the links between the different groups within the Fourth Internationalist Movement, reproduce part of their discussions and correspondence and situate them in the framework of the collapse of the Third International, the rise of fascism and the implications of the Second World War.
\end{abstract}

Keywords: Argentinian trotskyism - Trotskyist publications - Grupo Obrero Revolucionario - Liborio Justo - Fourth International

\title{
Introducción
}

El Grupo Obrero Revolucionario, liderado por Liborio Justo entre 1938 y 1941, editó junto a su prensa regular - La Nueva Internacional- una serie de diez folletos ${ }^{1}$ de unas treinta y cinco páginas promedio bajo el sello de Ediciones "Acción Obrera". Las publicaciones en cuestión, cuya autoría mayoritaria pertenece a Liborio Justo -"Quebracho"-, reconstruyen los inicios del trotskismo en Argentina y América Latina, plantean los vínculos entre las agrupaciones que adherían al "movimiento cuartainternacionalista", reproducen los debates y parte de la correspondencia entre ellos, y los sitúa en el contexto mundial del derrumbe la Tercera Internacional, el ascenso del fascismo y las implicancias de la Segunda Guerra Mundial.

Distribuidos por correo, a cambio de diez o veinte centavos de entonces, Ediciones "Acción Obrera" recibía solicitudes de envío desde numerosas ciudades del país -Buenos Aires, Mar del Plata, Rosario, Córdoba, Resistencia, Formosa, Mendoza- y desde países

\footnotetext{
${ }^{1}$ Cómo salir del pantano (1939), Nuestras perspectivas políticas (1939), Por el socialismo revolucionario y la Cuarta Internacional (1939), La revolución mundial y la traición stalinista (1939), Qué quiere la Cuarta Internacional (1939), Centrismo oportunismo y bolchevismo (1940), La Argentina frente a la Guerra Mundial (1940), La guerra imperialista y la revolución mundial proletaria. Manifiesto de la Cuarta Internacional (1940) Conversando con León Trotsky (1941), La agonía mortal del capitalismo y las tareas de la Cuarta Internacional. Tesis del Congreso de Fundación (1941).
} 
limítrofes como Bolivia o Uruguay². Aunque desconocemos exactamente su tiraje, la prohibición oficial de la circulación por correo de uno de los folletos permite hipotetizar una repercusión lo suficientemente amplia, como para interpretarla como preocupante por parte de las autoridades estatales.

Siete de los diez folletos contienen elaboraciones propias de Liborio Justo, mientras que los restantes tres reproducen en su totalidad documentos de otra autoría. Nos referimos a "Conversando con León Trotsky", una serie de entrevistas realizadas en México por Mateo Fossa a León Trotsky; "La guerra imperialista y la revolución mundial proletaria”, el manifiesto de la Cuarta Internacional y "La agonía mortal del capitalismo y las tareas de la Cuarta Internacional”, tesis del Congreso de Fundación de la Cuarta Internacional (1938).

$\mathrm{El}$ presente trabajo se propone, por tanto, analizar esta experiencia editorial inédita en la entonces breve historia del trotskismo argentino, en el marco de una preocupación más amplia por reconstruir el accionar político del Grupo Obrero Revolucionario y la Liga Obrera Revolucionaria ${ }^{3}$. En esta ocasión nos concentraremos en el análisis de los primeros tres folletos elaborados por Liborio Justo, completándolo luego con el resto de las publicaciones en un próximo artículo. El examen del contenido temático de los folletos -los cuales no han sido explorados con anterioridad en su conjunto- pone en evidencia un esfuerzo editorial que buscó, por un lado, comprender y dar a conocer las potencialidades y debilidades de las agrupaciones trotskistas para conformar la sección argentina de la Cuarta Internacional -a fines de caracterizar el tipo de intervención política que el Grupo Obrero Revolucionario debía implementar en ese sentido-; y, por otro, contribuir a la divulgación, local y en español, de los debates del marxismo a nivel internacional, y, consecuentemente a la formación teórica de la militancia cuartainternacionalista argentina.

Esta contribución pretende realizar un aporte a la Historia intelectual en un área -la historia de la IV Internacional en la Argentina- que permanece inexplorada por la literatura especializada. A tal fin, describiremos en primer lugar el contenido de las publicaciones, para luego efectuar un balance crítico de sus tesis.

\footnotetext{
${ }^{2}$ De ello da cuenta la correspondencia del partido que fuera archivada y conservada por la familia de Liborio Justo.

${ }^{3}$ Tesis Doctoral en curso inscripta en la Universidad Nacional de La Plata: "Hacia una definición de la formación socioeconómica argentina: El vínculo entre historia y política en la obra de Liborio Justo ("Quebracho")".
} 


\section{Cómo salir del pantano (enero de 1939)}

En enero de 1939, a cuatro meses de la fundación de la IV Internacional, Liborio Justo publica Cómo salir del pantano. Hacia la formación de la Sección Argentina del Partido Mundial de la Revolución Socialista, bajo el seudónimo de "Quebracho". Se trata de un extenso folleto de 34 páginas que el autor dedica al análisis del "movimiento bolcheviqueleninista" en la Argentina, y a las tareas que éste debe realizar a fin de alcanzar la superación de los defectos que lo aquejan. Influenciado por el ¿Qué hacer? de Lenin y por La Revolución Permanente de Trotsky, Justo da cuenta de un importante bagaje teórico proveniente de la literatura clásica del materialismo histórico. En efecto, el folleto que nos ocupa contiene referencias no sólo a Lenin y a Trotsky, sino también a Rosa Luxemburg, Georgi Plejánov y Franz Mehring, entre otros.

Estructurado en cinco apartados, el autor dedica el primero de ellos a dar respuesta al siguiente interrogante: "¿por qué hasta hoy no ha llegado a formarse una organización

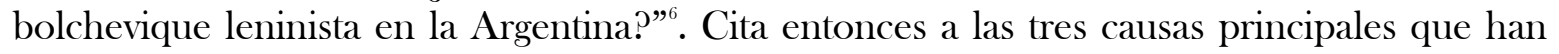
confluido, desde su perspectiva, a esta situación: “a) la falta de condiciones objetivas; b) la influencia de una larga tradición democrático-reformista y c) la constitución individual y la falta de teoría y de espíritu revolucionario de los miembros del movimiento que aspiraba a constituirse en organización bolchevique leninista entre nosotros" ". La falta de condiciones objetivas se vincularía, en primer lugar, con la creación de un "espíritu conformista" en la Argentina, como consecuencia de haber atravesado con éxito relativo la crisis mundial de 1929-1934, impidiendo la formación de una corriente revolucionaria. En segundo lugar, la "larga tradición democrática y reformista en nuestro proletariado" habría obstaculizado el "señalamiento de un camino revolucionario", como sí habría sido indicado en Brasil o Chile por la intervención de la Tercera Internacional. Estas particularidades argentinas habrían conducido a una situación de claudicación revolucionaria y a un movimiento bolchevique leninista sin coordinación ni orientación'. Los pormenores de esta caracterización, son extensamente detallados en los siguientes apartados.

En la segunda sección, Justo emprende una "síntesis del movimiento bolcheviqueleninista en la Argentina”, pasando revista por la breve historia del trotskismo en nuestro

\footnotetext{
${ }^{4}$ Quebracho, Cómo salir del pantano. Hacia la formación de la Sección Argentina del Partido Mundial de la Revolución Socialista (4 ${ }^{\circ}$ Internacional). Comentarios y perspectivas (Buenos Aires: Ediciones Acción Obrera, 1939).

5 Justo utiliza indistintamente "movimiento bolchevique-leninista" y "movimiento trotskista".

${ }^{6}$ Quebracho, Cómo salir del pantano...3.

${ }^{7}$ Quebracho, Cómo salir del pantano... 4.

${ }^{8}$ Quebracho, Cómo salir del pantano...4-5.
} 
país. De acuerdo a su reseña, el primer grupo trotskista fue constituido por Camilo López', cuya existencia es caracterizada como efímera. Luego de su desaparición, el movimiento bolchevique-leninista se habría desarrollado alrededor de Héctor Raurich ${ }^{10}$, Antonio Gallo ${ }^{11}$ y Pedro Milesi ${ }^{12}$, hasta que el primero de ellos se habría alejado voluntariamente de la militancia trotskista. Los grupos de Antonio Gallo y Pedro Milesi se habrían disputado desde entonces la militancia del movimiento, hasta que en 1934 Milesi fue expulsado de su grupo, produciéndose finalmente la unificación del grupo de Gallo con Pedro Milesi. En 1935, el surgimiento del que luego se conocería como el "grupo de Córdoba", editor de la revista América Libre, y en Buenos Aires, la conformación de otra agrupación en torno a Carlos Liacho $^{13}$ habría marcado el "apogeo de la primera etapa del trotskismo en Argentina" ${ }^{14}$ Por

\footnotetext{
${ }^{9}$ De origen español, Camilo López fue militante del PC hasta que acompañó a José Penelón en su ruptura con el partido en 1927. En 1929, sin embargo, se aleja del Partido Comunista de la Región Argentina, para conformar junto a Robert y Manuel Guinney, el primer Comité Comunista de Oposición en la Argentina, el cual se transformó en 1930 en Izquierda Comunista Argentina. En 1933, en desacuerdo por la designación de Pedro Milesi como Secretario General del partido, renunció a ICA. Horacio Tarcus y Laura Ehrlich, Diccionario biográfico de la izquierda argentina: de los anarquistas a la "nueva izquierda" $1870-1976$ (Buenos Aires: Emecé, 2007) 375.

${ }^{10}$ Nacido en Mar del Plata el 8 de agosto de 1903, Raurich fue "abogado, filósofo, crítico de arte, poeta, militante e intelectual comunista de izquierda, luego trotskista y finalmente socialista". Tarcus y Ehrlich 554.

11 Antonio Gallo nació en Buenos Aires en c.1913, fue ensayista político y militante trotskista. Inicia su militancia en la Juventud del Partido Socialista y publica, desde muy joven, artículos en el diario La Vanguardia y en la revista Claridad. Tras el golde de Estado de 1930 es detenido y consigue ser liberado gracias a contactos de su madre. Viaja a España en 1931 como parte de una delegación socialista que pretende tomar contacto con la República española. Tras su regreso a Argentina, toma contacto con el primer grupo comunista de oposición, la Izquierda Comunista Argentina, pero finalmente no lo integra. Publica, en cambio, junto a otros trotskistas y miembros del PC la revista Actualidad. Hacia 1933 conforma la Liga Comunista Internacionalista que en 1935 se fusionará con el grupo de David Siburu. En 1935, frustrada la fusión, se reagrupará junto a Liborio Justo, Mercedes Bacal y Aquiles Garmendia y editarán el periódico Nuevo Curso. Tarcus y Ehrlich 235-236.

${ }^{12}$ Pedro Milesi nació en Buenos Aires el 8 de octubre de 1886. Fue trabajador municipal y dirigente sindical trotskista. Milita inicialmente en el Partido Socialista y luego se afilia, en la década de 1920 al Partido Comunista. En 1922 es expulsado del PC tras sostener el frente único entre el PS y el PC. Reingresa al PC luego del golpe de Estado de 1930, pero romperá con él en 1932 para sumarse a la Izquierda Comunista Argentina. Protagonizará desde las páginas del periódico partidario, Tribuna Leninista, un fuerte debate con la publicación del grupo de Antonio Gallo, Nueva Etapa. Sin embargo, en 1935 ambos grupos se reunifican. Expulsado en 1936, editará la revista Inicial, de cuyo núcleo surgirá una nueva agrupación trotskista: la Liga Obrera Socialista Tarcus y Ehrlich 423-424.

${ }^{13}$ Trotskista bonaerense editor de la revista Transición. Periodista del diario La Razón. Fomentó la práctica del entrismo en el Partido Socialista Obrero e integró una fracción de este que se caracterizaba por la edición del periódico Frente Proletario. Ernesto González, "Los trotskistas de la Argentina durante la 'Decada
} 
su parte, a fines de 1936 y comienzos de 1937 se alcanzó el cénit de la declinación del movimiento, "después del cual comienza un nuevo período ascendente, iniciado en la segunda mitad de 1937" ${ }^{15}$, el cual se caracterizará por la incorporación de nuevas expresiones políticas y por la multiplicación de su militancia. Justo mismo representa una de estas incorporaciones, por lo que opta por describir esta nueva etapa a partir de su propia experiencia, en el tercer apartado del folleto que nos ocupa.

Nuestro autor abre el tercer acápite narrando en primera persona su relación con la militancia política. Su relato devela que había descubierto su condición de comunista y trotskista en 1933 y que ya por entonces había decidido ingresar a las "filas stalinistas", antes de aparecer públicamente como trotskista: “consideraba que a los stalinistas había que utilizarlos (...) para ponerme por su intermedio en contacto con la nada trabajadora que los sigue y adquirir entre ella un nombre" ${ }^{" 16}$. Por su parte, el movimiento era descripto como "mediocre, sin energías ni verdadero espíritu revolucionario": "me di cuenta que el trotskismo en el país estaba estancado en un pantano pestilente en el que no era posible entrar sin taparse las narices ni llenarse de lodo" ${ }^{17}$. Posteriormente, nuestro autor enumera a los primeros trotskistas argentinos con los que toma contacto -Héctor Raurich y Antonio Gallo, Carlos Liacho, Pedro Milesi- y lo estéril de estas experiencias desde su perspectiva. Frente a la decisión mayoritaria del movimiento trotskista de integrar el Partido Socialista Obrero, Justo creía que lo adecuado era que quienes eran contrarios a esta estrategia, también se organizaran, pero en una organización nueva. Sin embargo, a mediados de 1937 advirtió que no era el deseo del resto de sus compañeros de tendencia, por lo que abandonó la iniciativa momentáneamente. Concentró sus esfuerzos, en cambio, en editar un órgano. Mientras gestionaba los contactos pertinentes, Justo publicó, con su propio peculio, un boletín mimeografiado cuyo tiraje ascendió a 500 ejemplares: Información. Por un Partido Marxista Revolucionario y la Cuarta Internacional. Asimismo, editó dos periódicos de número único, de 2.000 ejemplares cada uno: España Obrera y Piquete, los cuales, de acuerdo al autor, constituían los primeros en su formato al interior de la prensa bolcheviqueleninista. El 7 de noviembre de 1937, con motivo de la recepción de una carta de Diego Rivera $^{18}$ en la que solicitaba el envío de tesis partidarias y la designación de delegados a una

Infame"", en El trotskismo obrero e internacionalista en la Argentina. Del GOM a la Federación bonaerense del PSRN (1943-1955) (Buenos Aires: Antídoto, 1995) 61-63.

${ }^{14}$ Quebracho, Cómo salir del pantano... 7.

${ }^{15}$ Quebracho, Cómo salir del pantano...

16 Quebracho, Cómo salir del pantano...8.

17 Quebracho, Cómo salir del pantano...

${ }^{18}$ La carta fue afortunadamente conservada en el archivo personal de Liborio Justo. Fechada en la ciudad de México el 21 de octubre de 1937, estaba dirigida directamente a Agustín Bernal, otro de los seudónimos de Liborio Justo. El material que solicitaba se vinculaba a las tesis vinculadas con la Argentina y con los países

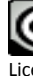


Conferencia que se realizaría en la ciudad de México la última semana del mes de diciembre de 1937, sobre la cuestión latinoamericana y como anticipo a la Conferencia PanLatinoamericana, Liborio Justo convocó a una reunión "como individuos" y no como grupos, a los miembros del movimiento trotskista a fin de contestar la misiva. Aprovechó entonces la ocasión para recordar la necesidad de publicar conjuntamente un órgano propio y se acordó la edición de lo que después se conocería como Nuevo Curso. Finalmente no participaron de la iniciativa Carlos Liacho -debido a su intención de intervenir como Partido Socialista Obrero-, Pedro Milesi -quien anunció que se separaba y que publicaría su propia revista- ni Antonio Gallo -quien adujo motivos personales vinculados a su casamiento-.

Fruto de un estilo de escritura militante mordaz y punzante, Justo entremezcla en el cuarto apartado de este folleto, la crítica política a los referentes del trotskismo argentino, con el cuestionamiento a sus características personales y/o físicas. Son objeto de una crítica despiadada Héctor Raurich, Antonio Gallo, Carlos Liacho. Pedro Milesi, David Siburu ${ }^{19}$, De Peniale, Juana Palma ${ }^{20}$ y Aurelio Narvaja ${ }^{21}$. El esquema de análisis se reitera: descripción de la personalidad a partir de la propia experiencia del autor del folleto, referencia a la existencia o no de publicaciones propias y examen del bagaje teórico-político. El balance general, en ese sentido, va a tono con las descripciones particulares:

En cerca de diez años de existencia del movimiento en la Argentina, ningún bolchevique-leninista ha sido capaz de elaborar una obra orgánica ni de dar un programa al movimiento o estudiar el medio en que debe desenvolverse. Y hay más, la mayoría de sus pretendidos dirigentes y grandes teóricos ni siquiera han publicado simples artículos ni dado a luz ninguna muestra de sus elucubraciones ${ }^{22}$.

limítrofes, según el siguiente esquema: 1) Exposición sinóptica de las condiciones históricas: económicas, sociales (situación de clases), políticas; 2) Líneas de desarrollo: crecimiento económico, definición de clases, crecimiento de las diferencias entre ellas; 3) Desarrollo político: partidos y su delineación clasista, sus diferencias, sus luchas; 4) Perspectivas: de desarrollo económico, social-político y de nuestra organización y trabajo Diego Rivera, "Carta de Diego Rivera a Agustín Bernal”, 21 Oct. 1937.

${ }^{19}$ Dirigente trotskista de la ciudad de Rosario, Argentina. González 62.

${ }^{20}$ Seudónimo de Mercedes Bacal (Baikal, 18/12/1900 - Buenos Aires, 10/3/1990). Odontóloga de profesión, estuvo vinculada al grupo Insurrexit hasta su ingreso al Partido Comunista en 1920. En 1929 es expulsada por sus posicionamientos izquierdistas. A fines de la década del treinta practica la táctica de entrismo en el Partido Socialista Obrero. En 1940 participa de la Liga Obrera Socialista que lidera Antonio Gallo. Desde 1941 y hasta 1943 participa del Partido Obrero de la Revolución Socialista. En las décadas de 1960 y 1970 junto a Mateo Fossa milita en la Mesa Coordinadora Nacional de Organizaciones de Jubilados y Pensionados de la República Argentina.

${ }^{21}$ Dirigente trotskista de un grupo estudiantil de la ciudad de Rosario. González 62.

${ }^{22}$ Quebracho, Cómo salir del pantano... 12. 
Ya en el quinto apartado, agrega:

Hasta ahora el trotskismo en Argentina ha sido una verdadera tragedia de insignificancia, de mediocridad, de ineptitud, de simulación, de inercia y de simpleza (...) Trotsky bien podría haber dicho que 'sembró dragones y cosechó pulgas' (...) Porque el defecto principal del movimiento bolchevique-leninista en la Argentina, lo que explica su impotencia, su disgregación su esterilidad y pequeñez, es el haber estado constituido por individuos que, no sólo no son revolucionarios ni marxistas, sino que nada tiene que ver ni con Marx ni con la revolución (...) El principal defecto del trotskismo en la Argentina en su constitución puramente pequeño-burguesa, de "carreristas" (aspirantes a hacer carrera política) que han visto una puerta abierta y por ella se han lanzado en busca de un encumbramiento que les negó su clase de origen. La lucha por el socialismo se transforma en esta gente en un torneo para lograr posiciones personales. Por eso todos quieren ser el "jefe"

Hacia el final de su último apartado, Justo responde finalmente a la pregunta por el qué debemos hacer -en clara alusión leninista- para lograr coordinar una acción conjunta entre todas las expresiones del trotskismo argentino. En primer lugar, destaca la necesidad de publicar colectivamente "un órgano por medio de un Comité de redacción elegido por mayoría de votos en una asamblea general” que, a pesar de las diferencias, logre mantenerse "dentro de un plano de lucha de clases y de principios generales", puesto que lo primordial es "acostumbrarnos a la acción común, a la seriedad, y a tratar de ensanchar nuestras filas" ${ }^{24}$ A continuación, el autor de Nuestra Patria Vasalla, destaca ocho puntos que completarían el cuadro de tareas políticas del movimiento trotskista, a saber: a) Citando a La revolución permanente, Justo llama a redactar un programa que se ajuste a la realidad argentina, es decir, que tenga en cuenta las particularidades del país; b) Buscar en el movimiento calidad y no cantidad; c) Evitar las exclusiones, dando nuevas oportunidades a quienes "estén dispuestos a una acción común”; d) Apartar los elementos estalinistas; e) Disponer de "revolucionarios profesionales" que puedan dedicarse a tiempo completo de las tareas político-militantes; f) "Reivindicar la violencia revolucionaria como un arma de lucha del proletariado"; g) Encarar la acción continentalmente; y, h) Desarrollar "una acción amplia, enérgica y estar en todas las partes en que hoy los trotskistas brillan por su ausencia” ${ }^{25}$.

\footnotetext{
${ }^{23}$ Quebracho, Cómo salir del pantano... 29-30.

${ }^{24}$ Quebracho, Cómo salir del pantano... 31.

${ }^{25}$ Quebracho, Cómo salir del pantano... 32-34.
} 


\section{Nuestras perspectivas políticas (abril de 1939)}

Coincidiendo con la publicación del primer número del periódico La Internacional bajo su dirección, Quebracho publica Nuestras perspectivas políticas, un folleto que tenía por objetivo "contribuir a preparar el camino hacia la formación de un partido revolucionario marxista-leninista en la Argentina” y concientizar a los militantes de que la tarea por delante no era otra que "preparar y conducir el movimiento revolucionario del proletariado" ${ }^{26}$. Con una estructura y un contenido similar a la de un programa partidario, Nuestras perspectivas políticas resume en doce puntos las tareas políticas que se desprendían de la caracterización que Justo efectuaba por entonces del movimiento bolchevique-leninista.

En primera instancia, Justo reconoce que "en los nuevos elementos está la esperanza del movimiento". Desde su perspectiva, la publicación del nuevo órgano demuestra la superación de una etapa que abre paso al recambio generacional y dirigente en el seno de la tendencia: el movimiento revolucionario marxista-leninista en la Argentina entra en una nueva fase de acción efectiva y de fundación verdadera de los cimientos del partido de la Cuarta Internacional (...) Esta nueva fase significará una renovación completa en todos los $\operatorname{aspectos}{ }^{27}$.

Asimismo, como consecuencia de la introducción de nuevos militantes inexpertos, Justo advierte que, para evitar caer en "extremismos infantiles", se deberá "estudiar con inteligencia la realidad en la que tenemos que actuar”. De acuerdo a Quebracho, este análisis identifica que: a) el accionar político a desempeñar por el movimiento trotskista en la Argentina no condice con el de un "grupo de agitación", sino con el de un "grupo de propaganda" que debe ocuparse de "crear un partido revolucionario y formar sus cuadros"; b) el período que transcurría por entonces (enero de 1939) debía caracterizarse como de "reflujo revolucionario"; c) en este contexto, debían adaptarse los militantes a las "condiciones de semi-ilegalidad precaria en que vive el país" ${ }^{28}$.

A continuación, nuestro autor se pregunta si el nombre del órgano recientemente publicado (La Internacional) indicaba que el estalinismo constituía una herencia que debía ser reivindicada. Quebracho aclara, entonces, que la denominación del periódico se eligió demasiado apresuradamente; pero que, como grupo, constituyen "una reacción en contra del stalinismo" y que su propósito "no es reformar la Tercera Internacional, sino crear la

\footnotetext{
${ }^{26}$ Quebracho, Nuestras perspectivas políticas, Quebracho. (Buenos Aires: Ediciones Acción Obrera, 1939$) 1$.

${ }^{27}$ Quebracho, Nuestras perspectivas políticas 2.

${ }^{28}$ Quebracho, Nuestras perspectivas políticas 4-5.
} 
Cuarta”. Sugiere entonces, el cambio de advocación, para no convertirse en "cómplices en un pasado de errores que ningún revolucionario puede olvidar”"

En cuarto lugar, Justo recalca que "no se trata sólo de ir a la masa, sino de crear los cuadros dirigentes capaces de nuclear a la vanguardia revolucionaria de esa masa y de conducirla" ${ }^{30}$. La formación surge como un imperativo de toda organización revolucionaria y para todos los aspectos del trabajo revolucionario: "debemos, pues, formar un cuadro de dirigentes altamente capacitados, tanto en la teoría como en la acción” ${ }^{31}$.

Aludiendo al concepto de "revolución permanente" de Trotsky, el cual preconiza el análisis de las particularidades nacionales como un paso previo a la determinación del accionar revolucionario, Quebracho propone evitar colocarse "en un terreno de internacionalismo abstracto" o de "nacionalismo estrecho", a fin de "asentarse en las realidades nacionales para cerrar el frente de la acción revolucionaria internacional”.

En cuanto a las actividades políticas propiamente dichas, éstas deberían concentrarse, según Justo, en la ciudad de Buenos Aires y sus alrededores, habida cuenta de su preponderancia industrial. Por otro lado, encara la necesidad imperiosa de reunir fondos para la causa. Los métodos de recolección quedarían librados "al espíritu de empresa y al ingenio de los compañeros”. En cuanto al terreno de acción militante, Quebracho considera que debía formarse, de manera inmediata, "células y fracciones sindicales, por insignificante que sean" ${ }_{32}$.

Acto seguido, Nuestras perspectivas políticas se ocupa del problema del trotskismo en el ámbito local y se pregunta si es posible la unificación del movimiento. Se informa, en primer lugar, la conformación del Grupo Obrero Revolucionario a partir del grupo editor del periódico La Internacional, al cual se habrían sumado los núcleos de Córdoba ${ }^{33}$ y La Plata $^{34}$, quedando por fuera las agrupaciones de Antonio Gallo y Pedro Milesi. Estos últimos habrían sido, desde la perspectiva de Justo, "los culpables directos del largo período de

\footnotetext{
${ }^{29}$ Quebracho, Nuestras perspectivas políticas 6-7.

${ }^{30}$ Quebracho, Nuestras perspectivas políticas 7.

${ }^{31}$ Quebracho, Nuestras perspectivas políticas 8.

${ }^{32}$ Quebracho, Nuestras perspectivas políticas 10.

${ }^{33}$ Hace referencia al grupo de Esteban Rey, Juventud Socialista 'José Guevara'. El grupo de Córdoba había manifestado inicialmente la intención de integrar el Grupo Obrero Revolucionario, pero se declaró posteriormente autónomo y concentró su actividad en el ámbito provincial Quebracho, Centrismo, oportunismo y bolchevismo (Buenos Aires: Ediciones Acción Obrera, 1940) 7.

${ }^{34}$ Alude al núcleo formado en torno a Reinaldo Frigerio, conocido entonces con el seudónimo de Jorge Lagos. Inicialmente conformó el GOR, pero se separó al poco tiempo, debido a desacuerdos en torno a la consigna de "liberación nacional”. Osvaldo Coggiola, Historia Del Trotskismo en Argentina y América Latina (Ediciones ryr, 2006) 48; Tarcus y Ehrlich 224.
} 
fracaso que nos ha precedido" ${ }^{35}$. El último grupo que Quebracho considera es aquel conformado por trabajadores judíos, "el Bund argentino". Los considera numéricamente poco relevantes, por lo que cree que se disolverán en la sección argentina de la IV Internacional, ni bien se conformara definitivamente. El paso siguiente, por tanto, que debía adoptar el movimiento trotskista argentino, debía ser, de acuerdo a Justo, la realización de un congreso general que constituya la sección argentina del partido mundial de la revolución socialista, seguido luego por un congreso sudamericano de secciones de la Cuarta Internacional.

\section{Por el socialismo revolucionario y por la Cuarta Internacional (mayo de 1939)}

El siguiente folleto publicado por Ediciones "Acción Obrera" consiste en la reproducción de una serie de once artículos que habían sido ya publicados por el autor en diferentes medios de prensa o propaganda y tres cartas dirigidas a la Juventud Universitaria de Bolivia, a José Penelón como Presidente del Partido Concentración Obrera y al embajador español en Argentina, Ángel Ossorio y Gallardo, respectivamente. En la revista Claridad se habían publicado ya seis de los nueve artículos; los cuatro restantes pertenecían al periódico editado por Liborio Justo en 1937, España Obrera; a la publicación mexicana Clave, al recientemente fundado La Internacional y al órgano del grupo BolcheviqueLeninista de Montevideo, Acción Socialista. En términos generales, los artículos tienen como tópico central al accionar contrarrevolucionario del estalinismo en España, Checoslovaquia, China, Francia, Argentina, Chile y Bolivia, destacando particularmente los aspectos nocivos de la política de constitución de frentes populares, tanto en Europa como en América Latina, como consecuencia de la injerencia de los partidos comunistas locales. En palabras de Justo:

Se reúnen aquí una serie de artículos y notas que forman parte de la batalla sostenida por el autor en los tres últimos años en defensa del socialismo revolucionario y por la formación de la Cuarta Internacional. A través de esta recopilación podrá verse que esa batalla no fue fácil, máxime cuando, quien la sostuvo, debió hacerlo, en esta parte del mundo, prácticamente solo. También será posible apreciar cómo se fueron cumpliendo inexorablemente las predicciones hechas en esos artículos, tales como la entrega de España, el apoyo estalinista al presidente Ortiz, etc., y otras que desgraciadamente aún

\footnotetext{
${ }^{35}$ Quebracho, Nuestras perspectivas políticas 11.
} 
están por realizarse. Una vez más se confirma aquí que la fuerza del marxismo reside en su capacidad de previsión ${ }^{36}$.

El folleto reproduce, en primera instancia, la carta pública mediante la cual Liborio Justo renuncia públicamente al Partido Comunista en noviembre de 1936. Las causas que allí enumera se vinculan con la publicación de una nota en el periódico partidario en el que, según nuestro autor, se lo acusa de extremista y se ridiculiza algunas de sus afirmaciones en torno a la defensa de la vía armada como resguardo ante el avance del fascismo. Justo descalifica fuertemente la posición "pacifista” del PC, tildándola de "pequeño-burguesa, timorata y reformista". Por otro lado, Quebracho muestra su disconformidad ante la conformación de Frentes Populares en Sudamérica, política que considera "un vuelco repentino hacia la derecha, después de un período de ultraizquierda” y producto de la “degeneración de la III Internacional”:

Empeñarse en hacer frente común con los radicales y los demócratas y ordenar a los afiliados votar por ellos en los comicios, como se hizo en las últimas elecciones, creyendo que con ello se combate el fascismo, significa redondamente adoptar la zarandeada línea del mal menor que, hace apenas dos o tres años, era calificada por los mismos que ahora la siguen como "la teoría de la traición permanente del proletariado" (...) En la formación de los Frentes Populares en Sudamérica se trata de repetir, ni más ni menos, la nefasta experiencia de olvidar la lucha de clases y colocar a los trabajadores a la zaga de la burguesía (...) Todo este nuevo camino (...) no es el resultado circunstancial de resoluciones locales ni el producto e la elucubración de ese cuerpo de mediocres pequeño-burgueses que dirigen aquí el partido (...) Todo esto es directamente el resultado de la degeneración que viene sufriendo la III Internacional, que en la época de Lenin fue el primer motor de la revolución mundial y que posteriormente, de transacción en transacción, de pacto en pacto con las potencias imperialistas, ha ido conduciendo al proletariado a derrota tras derrota, como son los casos más salientes los de China y Alemania ${ }^{37}$.

Justo pone de manifiesto lo que considera un error del PC: "Suponer que la burguesía puede hacer una revolución”, olvidándose de conquistar a las masas trabajadoras. De acuerdo a nuestro autor, la única manera de detener al fascismo era dotando de armas a los trabajadores y construyendo una nueva Internacional que "siga la línea bolchevique trunca".

El segundo artículo que reproduce el folleto tiene por objetivo indagar en la asunción a la Presidencia de Roberto Ortiz en 1938. En ese marco, Justo vierte sus apreciaciones en

\footnotetext{
${ }^{36}$ Quebracho, Por el socialismo revolucionario y por la Cuarta Internacional (Buenos Aires: Ediciones Acción Obrera, 1939) 3.

37 Quebracho, Por el socialismo revolucionario... 4-5.
} 
relación al gobierno de su padre, el Presidente saliente, el cual sólo le preocupa "como expresión de los intereses de la clase gobernante": "Significó para el país un notable afianzamiento de los intereses de las clases poseedoras y una entrega mayor de la economía argentina en manos del imperialismo, todo a costa de la masa de la población del país y principalmente de la clase trabajadora y productora" ${ }^{38}$. Según nuestro autor, Roberto Ortiz contaba con el apoyo de la Cámara de Comercio británica, puesto que había sido abogado de los ferrocarriles ingleses y había colaborado con la preparación de la Ley de Coordinación de Transportes. Era, desde la perspectiva de Justo, un agente inglés que obedecía las imposiciones imperialistas, tal como lo hacía el partido que lo había llevado de candidato, la Unión Cívica Radical Antipersonalista: "la Unión Cívica Radical no es más que otro partido burgués reaccionario, tan clerical y tan agente del imperialismo como la rama de la burguesía

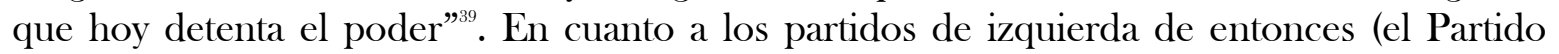
Socialista Obrero y el Comunista), ambos habían apoyado la candidatura radical "servilmente". Por tanto, la clave de los fraudes electorales estaba, de acuerdo a Justo, en la supeditación de Argentina a los intereses imperialistas británicos.

En el siguiente artículo que incluye el folleto, Justo responde a una serie de críticas que recibió por la publicación de la nota anteriormente reseñada, de Emilio Troise -Presidente de la Agrupación de Intelectuales, Artistas, Periodistas y Escritores (AIAPE) ${ }^{40}$ que el mismo Liborio integraba- y del Partido Socialista Obrero. A Emilio Troise le recrimina su defensa de José Américo de Almeida, Senador y Candidato Presidencial del Brasil, a quien consideraba un anticomunista confeso y un defensor de las compañías extranjeras instaladas en este último país; le reprocha, a su vez, la falta de valentía para "expresar en público las ideas favorables a la posición de León Trotsky" ${ }^{* 1}$. Por otro lado, reseña los cargos que el Partido Socialista Obrero presentaban contra él: No haber atacado al Partido Socialista (PS), no transigir con el Frente Popular y mantener una línea marxista intransigente. Respecto a la primera acusación, Justo la niega rotundamente, asegurando haber atacado el reformismo del PS. Respecto a la segunda acusación, nuestro autor denuncia la ausencia de principios marxistas en la formación de Frentes Populares: "El Frente Popular como acción de lucha

38 Quebracho, Por el socialismo revolucionario... 9.

39 Quebracho, Por el socialismo revolucionario... 10.

${ }^{40}$ La AIAPE fue una "organización antifascista de movilización de intelectuales" de aproximadamente 400 integrantes que desempeñó funciones entre 1935 y 1943. Publicó dos revistas propias Unidad y Nueva Generación. Andrés Bisso y Adrián Celentano, "La lucha antifascista de la Agrupación de Intelectuales, Artistas, Periodistas y Escritores (AIAPE) (1935-1943)," en El pensamiento alternativo en la Argentina del siglo XX: Tomo II, Obrerismo, vanguardia, justicia social (1930-1960), vols. (Buenos Aires: Editorial Biblos, 2006), 235-265.

${ }^{41}$ Quebracho, Por el socialismo revolucionario... 15. 
contra el fascismo no es más que un engaño y un crimen. La única lucha efectiva contra el fascismo es la formación del Frente Único proletario de todos los partidos y organizaciones obreras ${ }^{\star 2}$. Por su parte, la tercera acusación es aceptada orgullosamente por Justo.

A continuación, el folleto en análisis introduce la editorial del periódico de número único España Obrera. La publicación fue editada por Liborio Justo en noviembre de 1937, con motivo de la Guerra Civil Española entonces en curso. La editorial resalta el rol de los trabajadores españoles, quienes tomaron las armas por sí mismos, a pesar del sabotaje del gobierno del Frente Popular. Por otro lado, denuncia la acción del estalinismo, el cual

con el amparo de los partidos burgueses y bajo la inspiración del bloque imperialista anglo-francés -que domina a los gobiernos de Valencia y Barcelona- comenzó a hacer de perro de presa del capitalismo, persiguiendo y asesinando a los verdaderos revolucionarios y a los obreros que querían ganar la guerra haciendo la revolución ${ }^{43}$.

El próximo artículo que contiene la publicación analiza la "grotesca 'Paz de Munich” a la luz de la traición de la política de frentes populares, haciendo hincapié en los casos de Francia, España y Checoslovaquia. Respecto a Francia, Justo anticipaba el triunfo del fascismo:

Hoy Daladier ha mostrado las uñas y el establecimiento de un "gobierno fuerte" en Francia está a la orden del día. No sería de extrañar que el triunfo del fascismo sea el desenlace, el mismo fascismo que hizo creer a los obreros que el Frente Popular combatiría y que habrían de atraer si hacían huelgas y que llegará -si llega- precisamente porque esas huelgas no fueron más amplias y porque en lugar de apoyar a Blum, los trabajadores no lo sacaron de en medio para encargarse de su propio destino. El Frente Popular había cumplido su misión en Francia: destruir la revolución proletaria".

En relación a España, Quebracho intenta demostrar en qué medida el triunfo del Frente Popular no destruyó las organizaciones fascistas, sino que les permitió prepararse para el golpe de julio de 1936 y para el avance de la reacción, en términos generales. Checoslovaquia, por su parte, ha sido "vergonzosamente" entregada a partir del Pacto de Munich:

El pacto de las cuatro potencias bajo la batuta de Alemania e Italia entraba en efecto. La "democrática” Inglaterra y la Francia del Frente Popular, besaban la bota de Hitler. El proletariado checoslovaco, sintiéndose entregado, clamaba valientemente por armas, las

\footnotetext{
${ }^{42}$ Quebracho, Por el socialismo revolucionario... 17.

${ }^{43}$ Quebracho, Por el socialismo revolucionario... 21.

${ }^{44}$ Quebracho, Por el socialismo revolucionario... 26.
} 
que le fueron negadas por el "demócrata” Beneš quien prefirió, como expresión de democracia burguesa, entregarse al fascismo antes de confiar en la acción del proletariado $^{45}$.

En el séptimo artículo del folleto Justo indaga en el triunfo del Frente Popular chileno y en la medida en que estas circunstancias abrían camino hacia una nueva llegada al poder del General Carlos Ibáñez en Chile -lo que efectivamente ocurriría en 1952-:

El camino del Frente Popular, en Chile ya está señalado. También el actual presidente Alessandri llegó al gobierno en 1932 llevado por una coalición de izquierda y terminó apoyándose en la derecha. El mismo final ha de tener el candidato electo Aguirre Cerda y, si el proletariado de Chile no lo impide, ese apoyo sobre la derecha que ya ha comenzado a hacerse palpable antes de tomar el poder, terminará dando paso a la encubierta reacción fascista del general Ibáñez que aprovechará la primera oportunidad que se le presente para cobrarse su participación en la "brillante victoria del proletariado" de Chile ${ }^{46}$.

El siguiente artículo tiene como tópico central el "trágico" fin de la Guerra Civil Española. Allí se afirma que el posicionamiento del Grupo Obrero Revolucionario al respecto fue, desde un comienzo, la de sostener la acción independiente del proletariado revolucionario, como estrategia frente al avance del fascismo. Denuncia, por tanto, la política de colaboracionismo de clases que llevaron adelante los partidos Socialista y Comunista, la cual habría consumado la entrega de España en manos del fascismo:

El frente popular de los stalinistas claudicó frente al fascismo después de haber destruido en la España "leal" todas las conquistas alcanzadas por los obreros, después de haber ahogado en sangre el levantamiento de Barcelona de mayo de 1937 y de haber liquidado en los frentes a lo más selecto y combativo del proletariado revolucionario ${ }^{47}$.

En este marco, Justo propone denunciar la "traición" estalinista y su distinción entre "capitalismo bueno” y "capitalismo malo”: “Para nosotros el capitalismo es el enemigo, ya sea "democrático" o "fascista”! (...) ¡No es cierto, compañeros, que haya imperialismos 'buenos', es decir, amos 'buenos', e imperialistas 'malos’! ¡Para nosotros todos los amos son malos!"

\footnotetext{
${ }^{45}$ Quebracho, Por el socialismo revolucionario... 22.

${ }^{46}$ Quebracho, Por el socialismo revolucionario... 33.

${ }^{47}$ Quebracho, Por el socialismo revolucionario... 34.

${ }^{48}$ Quebracho, Por el socialismo revolucionario... 36.
} 
A continuación, nuestro autor reproduce una carta remitida a la Juventud Universitaria de Bolivia (JUB), en respuesta de una invitación que ésta enviase a Quebracho, con motivo del Cuarto Congreso de Estudiantes de Bolivia, a realizarse el 25 de diciembre de 1938. Ante la imposibilidad de asistir, Justo remite a la JUB algunas consideraciones. La primera de ellas indica que el movimiento socialista se encuentra en retroceso como consecuencia del avance del fascismo, el cual sólo puede ser vencido por medio de una revolución proletaria que destruya al capitalismo. En este sentido, considera que la Segunda y la Tercera Internacional han claudicado ante este objetivo, manteniendo el status quo y defendiendo a la democracia burguesa. En segundo lugar, finalmente, insiste en la necesidad de echar por tierra la distinción entre imperialismo democrático y fascista que propone la política de frentes populares, máxime teniendo en cuenta la injerencia de los Estados Unidos en el continente americano:

Estados Unidos se presenta como campeones de la democracia y utilizan y sostienen a nuestros peores dictadores; quieren aparecer como campeones de la libertad y subyugan a nuestros pueblos; se muestran como abanderados del antirascismo y esclavizan 13 millones de negros y desprecian a los latinoamericanos; se arrogan el papel de nuestros defensores y toman posesión militar de nuestro territorio; nos quieren presentar la amenaza nazi y ellos han sido los únicos que hasta hoy nos han invadido; sostienen y defienden la política de "puertas abiertas" en China, mientras que por intermedio de la doctrina Monroe, pretenden cerrar las puertas de la América Latina a todos los otros intereses que no sean los suyos ${ }^{49}$.

En 1939 Liborio Justo recibía una solicitud del Partido Concentración Obrera para que éste emitiera su opinión respecto de la posibilidad de constituir un frente popular de izquierdas entre los partidos Socialista, Socialista Obrero y Concentración Obrera para las elecciones a realizarse en marzo de 1940. Quebracho responde al pedido con una carta que reproduce el folleto, dirigida al Presidente de Concentración Obrera, José Penelón. Allí sostiene que resulta indispensable que se unan todos los partidos obreros, frente al contexto que transitaba el país por entonces, pero que no estaba de acuerdo con reducir el Frente a objetivos electorales, ni con la denominación que estaba adquiriendo, ni con la posibilidad de que pueda añadirse la Unión Cívica Radical:

El problema es más vasto y profundo y consiste en la realización, no de un confuso Frente Popular de Izquierdas (?), sino de un frente único proletario de todos los partidos y organizaciones obreras del país que encare, no la obtención de las bancas de la minoría en una elección de la Capital, sino la toma del poder por el proletariado con

${ }^{49}$ Quebracho, Por el socialismo revolucionario... 38. 
el fin de hacer desaparecer la actual organización social basada en la propiedad privada y establecer la sociedad sin clases, sin oprimidos ni opresores, la sociedad socialista ${ }^{50}$.

Nuestro autor no considera que la población pueda interesarse en una conjunción de partidos de izquierda, cuyos miembros apoyasen al entonces Presidente Roberto Ortiz. En ese sentido y en la misma carta, Justo recuerda haber predicho en 1937 el sostén del Partido Comunista al Presidente Ortiz y asegura que si el general Justo, su padre, regresaba al poder, se beneficiaría, a su vez, del mismo apoyo ${ }^{51}$. Respecto al frente de partidos de izquierda, por último, considera que sólo la acción independiente del proletariado, a través de un Frente Único Proletario, sería capaz de detener el avance de la reacción.

El próximo artículo que contiene el folleto, originalmente publicado en la revista Claridad en enero de 1937, se pregunta si la política de buen vecino estadounidense implicaba la desaparición del imperialismo. Justo responde inmediatamente que no, que lo que ocurría era exactamente lo contrario:

La nueva política norteamericana levantaba enorme resistencia en los países latinoamericanos, provocando la formación de una atmósfera anti-yanqui desfavorable para sus intereses comerciales, que era utilizada por sus antagonistas. Había, pues, necesidad de destruir ese sentimiento adoptando una nueva política exterior, la que debe ahora ser desenmascarada ante nuestras masas ${ }^{52}$.

Respecto a la promesa estadounidense de no intervenir en Cuba, Quebracho predecía:

En lo referente al abandono del derecho de intervención en Cuba, que le concedía la Enmienda Platt, es evidente, también, que no se trata más que de un golpe efectista, destinado a quedar reducido a una modificación en el papel, ya que con Enmienda Platt o sin Enmienda Platt, los Estados Unidos van a intervenir en Cuba para defender sus capitales tan pronto como los crean amenazados ${ }^{53}$.

Por su parte, la acción imperialista de los Estados Unidos en América del Sur es también percibida como en franca intensificación, no sólo por la Guerra del Chaco, sino también por las concesiones que se desprendían de los tratados de comercio. De allí que para Justo la consigna para las masas trabajadoras debía ser la de formar un gran partido marxista que luche por la revolución proletaria continental. Finalmente, a fines de 1936 tuvo

${ }^{50}$ Quebracho, Por el socialismo revolucionario... 41.

${ }^{51}$ Sin embargo, el General Justo no tendría la oportunidad de volver a dirigir los destinos del país.

${ }_{52}$ Quebracho, Por el socialismo revolucionario... 43.

${ }^{53}$ Quebracho, Por el socialismo revolucionario... 44. 
lugar en Buenos Aires la Conferencia Interamericana de Consolidación de la Paz en la que Justo participaría con su "acción antiimperialista" ${ }^{{ }^{54}}$. En este su posterior artículo, resumiría los que para él constituían las verdaderas causas y propósitos de la conferencia, a saber:

a) Consolidar la hegemonía norteamericana sobre la América Latina (...).

b) Luchar contra su rival, el imperialismo inglés, para lo cual se ha elegido como sede de la Conferencia el corazón mismo de la zona de influencia británica: Buenos Aires (...)

c) Regimentar a los países de su protectorado latinoamericano con vistas a la futura guerra con el Japón. El choque entre el imperialismo yanqui y el japonés es inevitable y será la culminación de la segunda guerra mundial (...)

d) Abrir las puertas a la importación de sus mercaderías en los países latinoamericanos, para lo cual trae, entre los principales propósitos de la Conferencia, un proyecto de tregua aduanera en el continente y el deseo de firmar nuevos tratados de comercio (...)

e) Coordinar medios para encarar y aplastar los sucesivos levantamientos obreros y la propagación del espíritu revolucionario y antiimperialista en nuestros países, lo que pone en peligro las inversiones yanquis en la América Latina y la segunda y tranquila obtención de sus superganancias.

El penúltimo artículo que integra el folleto conmemora el vigésimo aniversario de la Revolución Rusa. Publicado originalmente en el órgano del Partido Bolchevique-Leninista de Montevideo en noviembre de 1937, subraya de qué manera la Revolución se fue extinguiendo, para dar finalmente lugar, luego de la muerte de Lenin en 1924, a la capitulación de la Tercera Internacional. Quebracho detalla, a continuación, un largo listado de traiciones que el estalinismo habría propiciado, haciendo por ende un llamamiento a construir la Cuarta Internacional:

Toda la guardia vieja del bolchevismo en las cárceles o brutalmente asesinada. Todas las enseñanzas del gran jefe de Octubre olvidadas o tergiversadas (...) El partido mundial que él ejercitó para destruir el sistema capitalista, convertido en su más acérrimo defensor, y en el más abyecto lacayo de la burguesía. El gran caudillo del Ejército Rojo (...) desterrado, difamado y calumniado. La revolución derrotada en China. El fascismo triunfante en Alemania sin batalla ni resistencia. Perdida Austria. La URSS en la Liga de

\footnotetext{
${ }^{54}$ Con motivo de la celebración de la Conferencia Interamericana de Consolidación de la Paz, el entonces Presidente norteamericano Franklin Roosevelt visitaba la Argentina. En la ceremonia inaugural se preveía su conferencia, pero antes de que pudiera comenzar su disertación en el Congreso, Liborio alzó su voz al grito de “¡Abajo el Imperialismo!”. Quebracho fue violentamente detenido, pero su intervención alcanzaría repercusión mundial. Exiliado en una estancia de La Pampa, se dedicó a escribir su autobiografía, Prontuario.
} 
las Naciones (...) El instinto revolucionario de las masas engañado por medio de los Frentes Populares que sólo conducen a entregarlas ciegamente al fascismo que se pretende combatir. Los mercenarios de Stalin transformados en América Latina en agentes descarados del imperialismo yanqui (...) En Francia auspiciando la "unión sagrada” en defensa de la patria como los traidores social-demócratas en 1914. En Italia propiciando la alianza con los fascistas sobre la base del programa de Mussolini en 1919. En España traicionando ignominiosamente al proletariado declarándose contra toda socialización por el mantenimiento de la propiedad privada ${ }^{55}$.

Finalmente, el último artículo del folleto reproduce una breve nota denunciando los procesos de Moscú y una carta abierta de queja, firmada por varios intelectuales y militantes de izquierda, dirigida al embajador de España, Ángel Ossorio y Gallardo, con motivo de la prisión y juicio de militantes a cargo de las autoridades de la República Española, con la complicidad directa de los servicios secretos estalinistas.

\section{Comentarios finales}

Ediciones "Acción Obrera" nació como un emprendimiento editorial individual de Liborio Justo, hasta que se constituyó el Grupo Obrero Revolucionario a comienzos de 1939, momento en que la iniciativa se tornó colectiva. Sin embargo, a excepción de tres folletos -de divulgación de manifiestos de la IV Internacional- la autoría la conservará Justo, dando cuenta de un rol protagónico en el emprendimiento editorial. En su conjunto, las publicaciones brindan una aproximación a las tesis políticas sostenidas por el GOR en torno al movimiento obrero local, al rol de la Argentina en el seno de la Cuarta Internacional y al trotskismo como teoría para la acción en el contexto latinoamericano. Asimismo, ponen de manifiesto las tareas políticas que se desprenden de las caracterizaciones a las que arriba la organización.

En términos generales, los diez folletos reflejan un esfuerzo editorial inédito por su formato en el seno del trotskismo argentino, el cual pretende difundir en el contexto local las ideas y los debates que el marxismo suscita a nivel internacional, y bregar por la constitución de la Sección Argentina de la IV Internacional. Con este doble objetivo, Justo -quien da muestras de un acceso privilegiado a publicaciones del movimiento trotskista internacionallogra plasmar en las páginas de sus ediciones una lectura en clave materialista de los avatares del trotskismo vernáculo, latinoamericano y mundial. En ese sentido, los folletos suponen un

\footnotetext{
${ }^{55}$ Quebracho, Por el socialismo revolucionario... 48.
} 
testimonio -en primera persona y por uno de sus protagonistas- de los orígenes del trotskismo argentino.

Por otro lado, estas publicaciones reflejan en sus páginas -con las desmesuras propias de una escritura militante, pero con un sólido conocimiento de la literatura marxista clásica-, las tareas políticas que Justo entendía que debían llevarse a cabo en el seno del movimiento cuartainternacionalista. A saber, en primer lugar, llevar a cabo un diagnóstico de la situación de los cuadros trotskistas locales a fines de la década de 1930. En segundo lugar, superar la etapa de desavenencias personales y acordar la edición de un periódico colectivo (finalmente editado como La -Nueva- Internacional). En tercer lugar, unificar definitivamente los cuadros dispersos para conformar una única sección argentina de la IV Internacional. Y, por último, convocar a una gran conferencia de todos los nucleamientos nacionales.

El amplio bagaje teórico en el área del marxismo del que da cuenta Justo -incluyendo referencias no sólo a Karl Marx y Friedrich Engels, sino también a Georgi Plejánov, Lenin, Trotsky, Rosa Luxemburg, etcétera-, fue el que le permitió arribar a tesis materialistas propias sobre la realidad argentina y latinoamericana que desarrollará y ampliará luego, al momento de abandonar la esfera partidaria y de redactar sus obras de carácter socio-histórico más relevantes.

En ese sentido, la formación teórica de Justo en el ámbito del marxismo se muestra ya, a fines de la década de 1930, sumamente sólida, nutrida por literatura marxista y por publicaciones periódicas del movimiento trotskista internacional, tanto en español como en inglés y francés. La traducción y divulgación para un público que se percibe como ajeno a las discusiones teóricas propias del ámbito -militantes sin formación- constituyen, en sí mismos, méritos de estas publicaciones.

Por otro lado, las herramientas teóricas que el marxismo le proveyó a Justo, son las que posibilitaron que nuestro autor lograra anticipar la consecución de algunos eventos, tanto a escala local como latinoamericana. Nos referimos, por ejemplo, a la previsión del apoyo del Partido Comunista argentino al Presidente Ortiz o el desenlace de la Enmienda Platt y la intervención estadounidense en Cuba.

En suma, los folletos de Acción Obrera constituyen el germen inicial del andamiaje teórico central de Liborio Justo. Así, caracterizaciones que se tornarán centrales en obras posteriores -como aquella que señala a la Argentina como un país semicolonial dependiente-, se encuentran ya plasmadas entre las páginas de sus folletos.

El ocaso de la publicación de los folletos coincidirá con el fracaso de una de las tareas políticas que Liborio entendía que debía llevar a cabo el GOR -y que reflejaba en las páginas de sus publicaciones-: la unificación de todos los grupos trotskistas argentinos en una única sección. Este fracaso tendrá como desenlace la constitución de dos grandes tendencias: el 
Constanza Bosch, Los primeros folletos de ediciones "Acción Obrera". Una experiencia editorial en los orígenes del trotskismo argentino (1938-1941) / The first pamphlets of "Acción Obrera" editions. An editorial experience in the origins of Argentinian Trotskyism. Revista Izquierdas, $\mathrm{N}^{\circ}$ 23, abril 2015, ISSN 0718-5049, IDEA-USACH, pp. 1-22

Partido Obrero Revolucionario Socialista y la Liga Obrera Revolucionaria, en la que se reconfigurará el GOR.

Recibido: 12 diciembre 2014

Aprobado: 5 marzo 2015 
Constanza Bosch, Los primeros folletos de ediciones "Acción Obrera". Una experiencia editorial en los orígenes del trotskismo argentino (1938-1941) / The first pamphlets of "Acción Obrera" editions. An editorial experience in the origins of Argentinian Trotskyism. Revista Izquierdas, $\mathbf{N}^{\circ} 23$, abril 2015, ISSN 0718-5049, IDEA-USACH, pp. 1-22

\section{Bibliografía}

Bisso, Andrés y Adrián Celentano. 2006. "La lucha antifascista de la Agrupación de Intelectuales, Artistas, Periodistas y Escritores (AIAPE) (1935-1943).” En El pensamiento alternativo en la Argentina del siglo XX: Tomo II, Obrerismo, vanguardia, justicia social (1930-1960), 23565. Buenos Aires: Editorial Biblos.

Coggiola, Osvaldo. Historia Del Trotskismo en Argentina y América Latina. Ediciones ryr, 2006.

González, Ernesto. "Los trotskistas de la Argentina durante la 'Decada Infame.” En El trotskismo obrero e internacionalista en la Argentina. Del GOM a la Federación bonaerense del PSRN (1943-1955), 51-86. Buenos Aires: Antídoto, 1995.

Quebracho. Centrismo, oportunismo y bolchevismo. Buenos Aires: Ediciones Acción Obrera, 1940.

- Cómo salir del pantano. Hacia la formación de la Sección Argentina del Partido Mundial de la Revolución Socialista (4 Internacional). Comentarios y perspectivas. Buenos Aires: Ediciones Acción Obrera, 1939.

—. Nuestras perspectivas políticas. Quebracho. Buenos Aires: Ediciones Acción Obrera, 1939.

- 1939. Por El Socialismo Revolucionario y Por La Cuarta Internacional. Buenos Aires: Ediciones Acción Obrera.

Rivera, Diego. 1937. “Carta de Diego Rivera a Agustín Bernal,” 21 de octubre.

Tarcus, Horacio, and Laura Ehrlich. Diccionario biográfico de la izquierda argentina: de los anarquistas a la "nueva izquierda" 1870-1976. Buenos Aires: Emecé, 2007. 